\title{
Transgene transmission frequencies between cultivated strawberry (Fragaria $x$ ananassa Dutch) and other Fragaria species
}

\author{
A. Gargaro, S. Monticelli, C. Damiano and M.A. Palombi* \\ CRA - Centro di Ricerca per la Frutticoltura, Rome, Italy
}

Received 21 September 2011; accepted 19 January 2012

\begin{abstract}
The transmission of transgenes (uid-A and nptII) was studied in crosses between transgenic plants, with Fragaria $\mathrm{x}$ ananassa cultivar Teodora as the donor plant and various Fragaria species as recipient plants. GUS expression and kanamycin resistance were evaluated in embryos and in seedlings after aseptical germination, both in intra- and inter-specific crosses as demonstrated by different ploidy level. This expression in most of the $\mathrm{T}_{1}$ seedlings shows that one or more functional transgenes were transferred from $T_{0}$ plants to $T_{1}$ seedlings. These results, obtained in a greenhouse, confirm the possibility of genetic exchange both at the intra- and inter-specific level, though the inter-specific hybrids seem to have reduced germination ability. These observations need to be further investigated.
\end{abstract}

Keywords: Fragaria x ananassa Dutch, Fragaria vesca L., transgene expression, GUS activity, crop-wild hybrids

\section{Introduction}

Strawberry, of the genus Fragaria within the family Rosaceae, is one of the most economically important fruit crops worldwide due to its adaptability to various environmental growing conditions [1]. The development of in vitro regeneration and genetic transformation systems for the cultivated strawberry (Fragaria x ananassa) has opened up the opportunity for strawberry improvement through genetic engineering, in addition to traditional plant breeding techniques [2,3]. Genetic engineering and biotechnology applications are increasingly being used to improve strawberry qualities and expand the breeding base and germplasm utilization. Genetic engineering offers the potential to create novel varieties by selectively targeting a gene or a few heterologous traits for introduction into the strawberry genome, facilitating and speeding the process of obtaining desirable agronomical traits such as increased resistance to pests, herbicides, diseases, environmental stresses as well as enhancement of fruit qualities. Marker genes have been introduced into the cultivated strawberry and in other Fragaria spp. by Agrobacterium-mediated transformation and by electroporation of protoplasts $[4,5]$.

Transformation in plant crops could present problems in developing transgenic cultivars [6, 7], such as differences in expression level of the integrated transgene among transformation events. Cultivated strawberry is octoploid $(2 n=8 \times=56)$ which may pose problems for the analysis of transgene expression. Studies focused on transmission of transgenes are reported in different species such as Arabidopsis thaliana [8], tobacco [9] and rice [10]. In strawberry, trasmission of transgenes in F. vesca cv. Alpine [11] and in Fragaria x ananassa [12] showed the sexual transmission

*Corresponding author: M.A. Palombi, CRA - Centro di Ricerca per la Frutticoltura, Via di Fioranello, 52 , 00134 Rome, Italy. Tel.: +39 06 79348178; Fax: +39 06 79340158; E-mail: mariaantonietta.palombi@entecra.it. 
of transgenes to R1 generation progeny but the mechanisms of transmission are unknown. Understanding the transmission of transgenes is important for the development of transgenic cultivars. These cultivars are dependent upon the transformation event which results in the expression of the integrated transgene at a high and stable level over generations and environments.

In order to better understand the transmission of transgenes, we tested the horizontal transfer of transgenes from strawberry to related species including $F$. vesca. We focused our attention on this last species because it is present in different habitats in Italy and is related to cultivated strawberry. We presented some hypotheses with respect to the possibility of genetic exchange both at the intra- and inter-specific level and we also characterized the transformed plants of Fragaria x ananassa cv Teodora obtained, as reported in [13].

\section{Materials and methods}

\subsection{Characterisation of transgenic donor plants}

The donor plant Clone 10 was previously obtained from Fragaria x ananassa cv Teodora, transformed by Agrobacterium tumefaciens strain C5851 harboring the vector pGV3850 with uid-A and nptII genes [13, 14].

In order to characterize transgenic plants obtained according to [13], genomic DNA was isolated from $1 \mathrm{~g}$ of leaves of transgenic clones of Fragaria x ananassa cv Teodora: 10, 10a, 228, 230, 247, 252, 253, 257, 264,430 and 437 by using the "5 Prime" DNA extraction kit (Eppendorf).

Southern analysis was performed with $7 \mu \mathrm{g}$ of EcoRI-PstI (Invitrogen) digested samples; spermidine (final concentration of $0.6 \mathrm{mM}$ ) was added to the digestion mix to ensure effective cutting of the DNA by restriction enzymes. Restricted DNA was separated on $1 \%$ (w/v) agarose gel, blotted onto positively charged nylon membranes (Roche Applied Science) and fixed by UV irradiation. Filters were probed with a digoxigenine-labelled fragment (Roche Applied Science) of the uid-A and nptII genes. Both of these were isolated from the plasmid vector pGV3850 and prepared by PCR following the supplier's instructions, using the pairs primer reported in [15].

\subsection{In vivo pollination}

In a test for potential gene flow, potted plants of non-transgenic species of Fragaria (Table 1) acclimatized in a glasshouse, were used as recipient plants and fertilized using the pollen of transgenic Fragaria x ananassa cv Teodora clone 10. Pollen was collect by emasculation of blossoms, dried under an incandescent lamp and stored at $4^{\circ} \mathrm{C}$. Pollen viability was detected by fluorescence emission under UV in a solution of fluorescein diacetate $0.5 \%$. Germinability was assessed by observing the development of the pollen tubes under the microscope, after incubation at $20^{\circ} \mathrm{C}$ for $6 \mathrm{hrs}$ on a medium containing yeast extract $1 \mathrm{~g} \mathrm{~L}^{-1}$, sucrose $100 \mathrm{~g} \mathrm{~L}^{-1}$, boric acid $100 \mathrm{mg} \mathrm{L}^{-1}$, agar $10 \mathrm{~g} \mathrm{~L}^{-1}$. For each sample and for both viability and germinability, a minimum of 400 pollen grains were numbered. Recipient plants

Table 1

Cross pollination of different Fragaria spp

\begin{tabular}{lcccc}
\hline Donor plant & $\begin{array}{c}\text { Recipient } \\
\text { plants }\end{array}$ & Ploidy & $\begin{array}{c}\text { No. of pollinated } \\
\text { flowers }\end{array}$ & $\begin{array}{c}\text { No. of achenes } \\
\text { collected }\end{array}$ \\
\hline & Clone '10' & $8 n$ & 17 & $382(20+362)$ \\
& cv Capitola & $8 n$ & 15 & $29(8+21)$ \\
Fragaria x ananassa & F. virginiana & $8 n$ & 20 & $102(16+86)$ \\
cv 'Teodora' Clone 10 & F. chiloensis & $8 n$ & 8 & 0 \\
& F. moscata & $6 n$ & 24 & $185(133+52)$ \\
& F. vesca cv Ilaria & $2 n$ & 21 & $152(24+128)$ \\
& F. vesca cv Snovit & $2 n$ & 22 & $86(12+74)$ \\
& F. vesca cv Zimbaro & $2 n$ & 31 & $266(221+45)$ \\
\hline
\end{tabular}


were emasculated prior to manual pollination. Pollination was carried out in the glasshouse, for a period of 3 weeks (March-April 2006) and each flower was pollinated twice and isolated using a bag. Achenes were collected from the mature fruits.

\subsection{Evaluation of transmission of transgenes to the progenies}

In order to evaluate the transmission of transgenes, achenes were divided in two sets: the first was directly used to perform GUS histochemical assay (Fig. 3a) performed according to [17] with modifications. Samples were incubated overnight at $37^{\circ} \mathrm{C}$ in a solution of $3 \mathrm{mM}$ 5-bromo-4-chloro-3indolyl-d-glucuronide-cyclohexy (x-Gluc, Sigma), $0.4 \mathrm{mM}$ potassium ferricyanide, $0.05 \mathrm{mM}$ potassium ferrocyanide, $10 \mathrm{mM}$ EDTA, $10 \mathrm{mM}$ DL dithiotreitol, $0.1 \%$ triton $\mathrm{x}-100$ and $20 \%$ methanol in $50 \mathrm{mM}$ sodium phosphate buffer $(\mathrm{pH} 7.0)$. Chlorophyll was then removed with a solution of methanol-glacial acetic acid $(3: 1 \mathrm{v} / \mathrm{v})$ for three hours and the explants were fixed in $70 \%$ ethanol. The second group of achenes was sterilised and placed on germination MS medium [16] content nicotinic acid $1 \mathrm{mg} \mathrm{L}^{-1}$, piridoxine $1 \mathrm{mg} \mathrm{L}^{-1}$, thiamine $1 \mathrm{mg} \mathrm{L}^{-1}$, inositole $100 \mathrm{mg} \mathrm{L}^{-1}$, sucrose $30 \mathrm{~g} \mathrm{~L}^{-1}, \mathrm{pH}$ 5.6. Plants obtained were growth on a MS propagation medium containing giberellic acid $\left(\mathrm{GA}_{3}\right) 0.1 \mathrm{mg} \mathrm{L}^{-1}$, benzyladenine (BA) $0.1 \mathrm{mg} \mathrm{L}^{-1}$, indole-3-butyric acid (IBA) $0.3 \mathrm{mg} \mathrm{L}^{-1}$, sucrose $30 \mathrm{~g} \mathrm{~L}^{-1}, 50 \mathrm{mg} \mathrm{L}^{-1}$ of kanamycin, $\mathrm{pH} 5.7$, to test kanamycin resistance. Leaves from the same plants were also used to perform both GUS histochemical assays as above reported (Fig. 3b) and PCR analysis for $n p t I I$ and uidA genes. DNA extraction for PCR analysis was performed as reported for Southern hybridisation analysis. Amplifications were conducted in a Biometra T thermal cycler, with a preliminary step of 5 min at $95^{\circ} \mathrm{C}, 30$
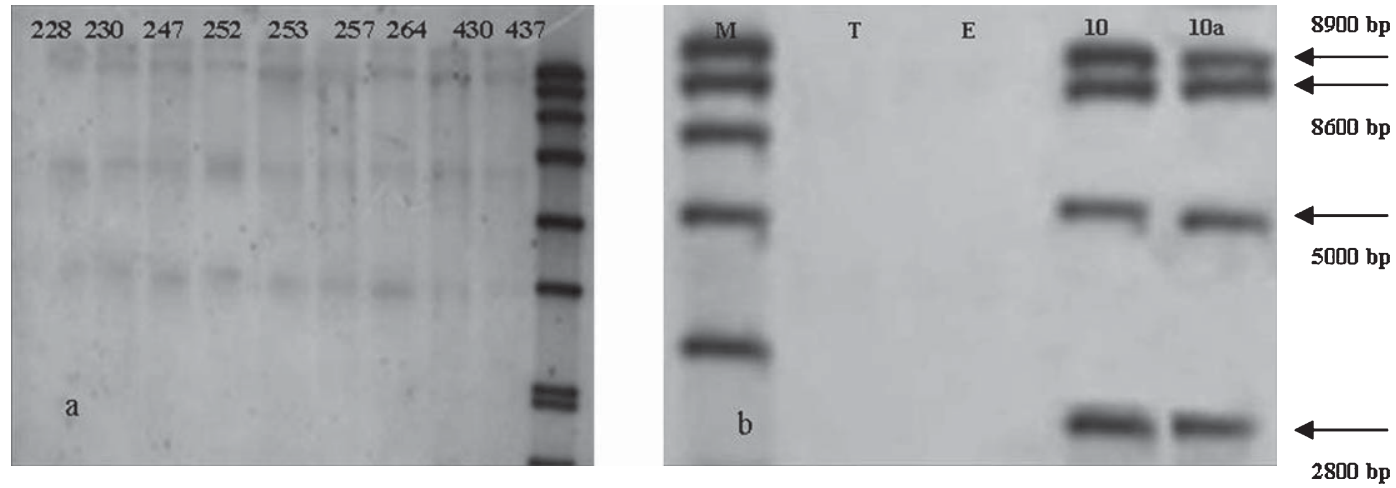

Fig. 1. a) Southern blot analysis of nptII gene. (M, DNA Molecular weight marker VII Dig-labelled; b) T, cv Teodora non-transformed; E, cv Egla, non-transformed).
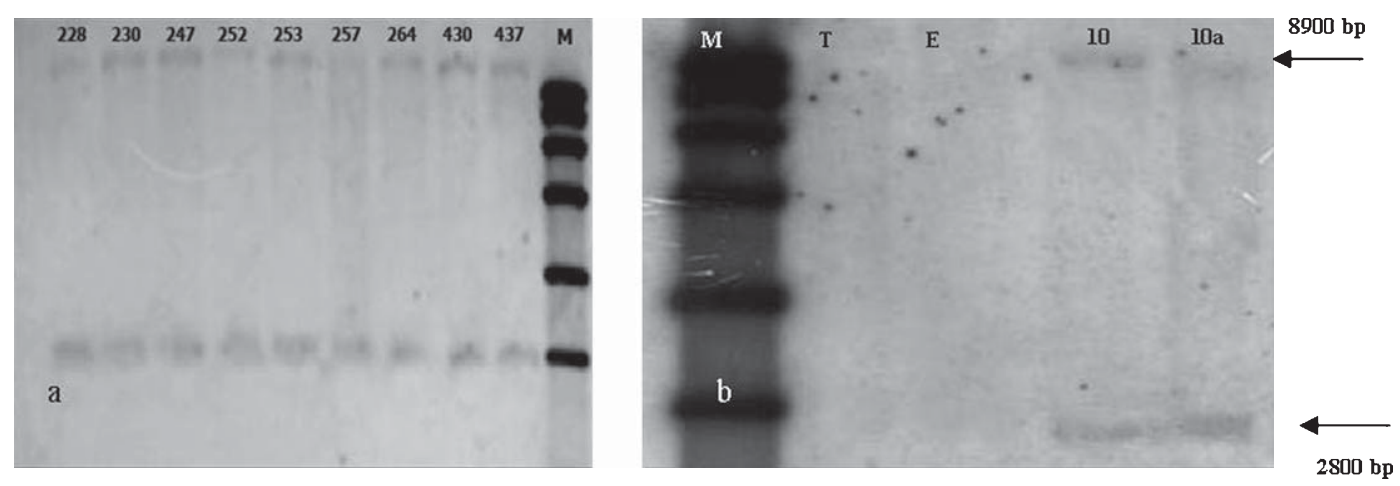

Fig. 2. a) Southern blot analysis of uidA gene. (M, DNA Molecular weight marker VII Dig-labelled; b) T, cv Teodora non-transformed; E, cv Egla, non-transformed). 

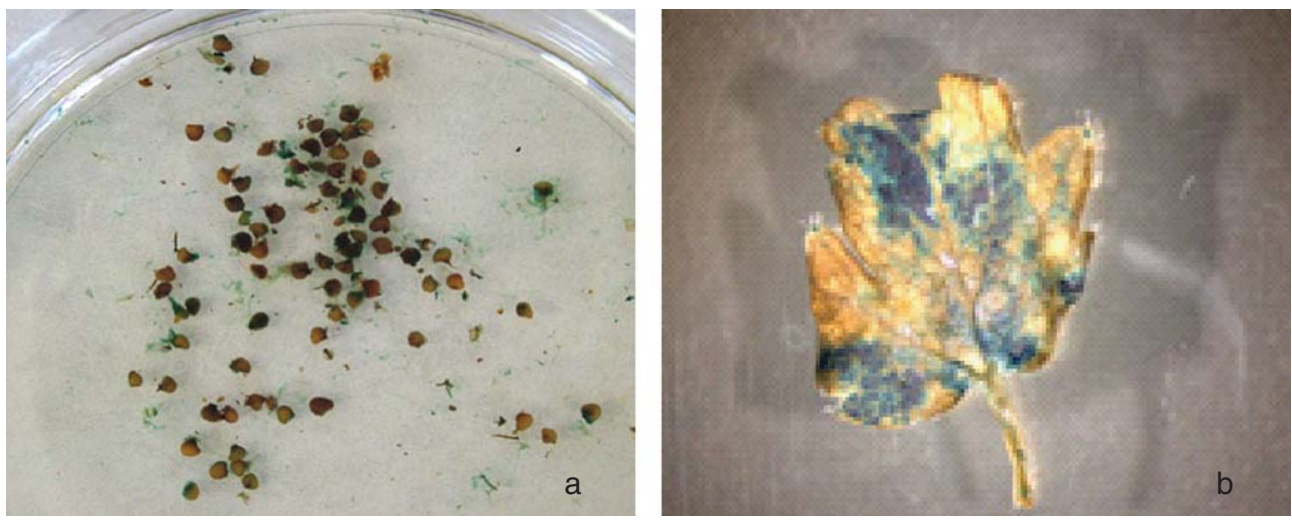

Fig. 3. GUS histochemical assay in achenes (a) and in plants obtained from seeds (b).
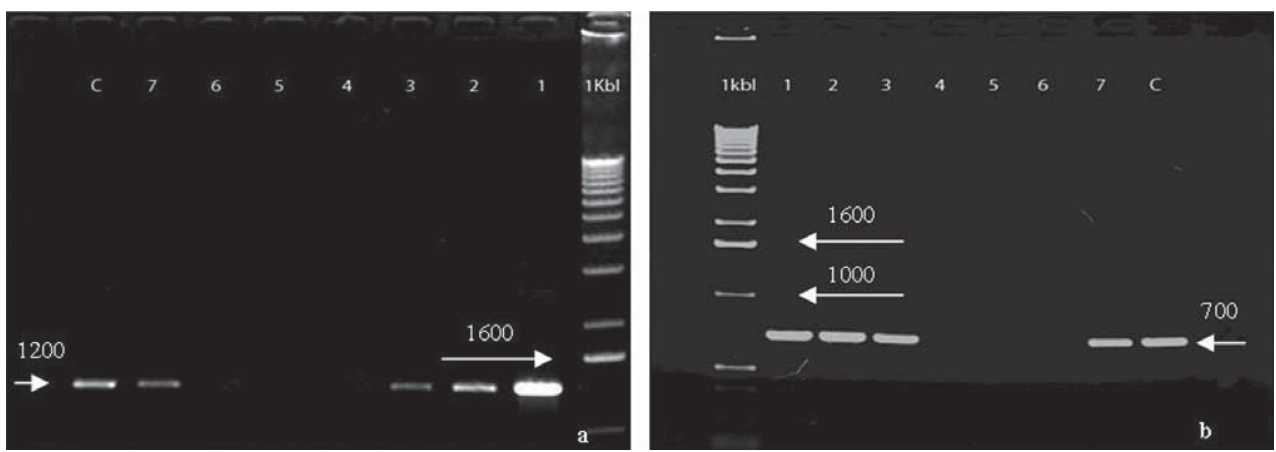

Fig. 4. PCR amplification of uidA (a) and nptII (b) pair-primers in different cross-pollination plants, derived from germinated seeds. (C, pGV3850 positive control; 1, F. moscata; 2, F. virginiana; 3, F. x ananassa cv Teodora clone 10; 4, F. x ananassa cv Capitola; 5, F. vesca cv Snovit; 6 , F. vesca cv Ilaria, 7, F. vesca cv Zimbaro.).

cycles of $60 \mathrm{~s}$ at $95^{\circ} \mathrm{C}, 60 \mathrm{~s}$ at $55^{\circ} \mathrm{C}$ and $2 \mathrm{~min}$ at $72^{\circ} \mathrm{C}$ and a final step of $10 \mathrm{~min}$ at $72^{\circ} \mathrm{C}$ using $25 \mathrm{ng}$ total DNA, $1 \mathrm{X}$ PCR buffer (Qiagen), $1.5 \mathrm{mM} \mathrm{MgCl} 2,0.2 \mathrm{mM}$ of each dATP, dCTP, dGTP and dTTP, (Invitrogen); 0,4 mM of each forward and reverse primer and 1U Taq DNA polymerase (Qiagen). Primers sequences were: 5'-GGT GGG AAA GCG CGT TAC AAG (forward) and 5'-TGGCGGAAGCAACGCGTAAAC (reverse) for uidA (1200 bp) (Fig. 4a) and 5'-GAC TGG GCA CAA CAG ACA ATC (forward) and 5'-ATC GGG AGC GGC GAT ACC GTA (reverse) for $n p t I I(700 \mathrm{bp})$ (Fig. 4b). Fragments were separated by electrophoresis on $1.2 \%$ agarose gel in TBE (Tris-Borate EDTA) $0.5 \mathrm{X}$ and stained in ethidium bromide.

\section{Results and discussion}

\subsection{Characterisation of transgenic plants}

In order to characterize the transgenic clones obtained [13] as well as the donor plant (clone 10), Southern hybridisations were carried out using nptII and uid-A labelled probes. Results for EcoRI-PstI digestion are reported in (Fig. 1a, b). A double digestion was necessary because it was not possible to hybridise EcoRI-digested DNA from transgenic plants with dig-labelled nptII probes (data not shown). Hybridisation showed four fragments, ranging from $8.9 \mathrm{~kb}$ to $2.8 \mathrm{~kb}$ in length, and confirmed the integration of transgenes. Normally, to estimate $n p t I I$ copy number, bands of different sizes are considered independent integration events and transgene copy number is estimated from 
the number of fragments exhibiting comparable hybridisation intensity. Because we used two restriction enzymes to digest the DNA, and one of these, PstI, showed the ability to cut within nptII gene, it would be inappropriate to estimate of nptII copy number as above. To better understand this aspect, a further Southern hybridisation using uid-A probe was performed (Fig. 2a, b) and it produced two fragments of $8.9 \mathrm{~kb}$ and $2.8 \mathrm{~kb}$ in length. When plants are transformed by two different genes and are analysed by Southern hybridisation using probes from both of these genes, results confirm the same copy number of genes, as shown in apple [18] and peas [19]. In our case, the PstI-DNA digestion could cause the breaking of the T-DNA cassette and, consequently, the hybridisation could generate "false positives". Finally, at least one un-truncated transgene copy was integrated in strawberry plants, without excluding the possibility of multiple copy integration, as reported in Citrus [20, 21], in Festuca [22] and strawberry [23, 24]. For these species expected fragments confirmed the insertion of one copy of the transgene, while the presence of different transgenic lines showed additional bands of higher molecular weight, which suggest that rearrangements had affected the T-DNA cassette.

Our data also confirm the stability of transgenes, obviously not in terms of inheritance because we would need to go through at least one sexual generation to state this, but only in terms of "stabilitise" the transgenes in the regenerated plants. In fact, hybridisation results from transgenic clones 10 and further regenerations (10a, 228, 230, 247, 252, 253, 257, 264, 430 and 437) obtained from the stipules of transformed plant [13] show the same band pattern. The use of this procedure is justified by the fact that crown galls induced by A. tumefaciens are chimeric tissue. In fact the hormone (auxin and cytochinin) -synthesizing enzymes coded by the T-DNA genes, modify both transformed and non-transformed cells [25-27]. Therefore the tissue transformed by disarmed A. tumefaciens (but also any other transformation procedure) could harbour both transformed and non-transformed cells. As a result, the regenerated plants could be chimeric because of the foreign genes. The extent of chimeric tissues, in relation to the proportion of transformed and non-transformed cells, would depend on the effective number of transformed cells in a given area. Thus, repeating the regeneration using transgenic tissue as explants and adding kanamycin (selective agent) to the medium, it is possible to stabilise transgenes in the regenerated plants.

\subsection{In vivo pollination and evaluation of transgenes transmission to the progenies}

In the donor plant, pollen viability and germinability ranged from $20 \%$ to $95 \%$ and from $4.3 \%$ to $55.7 \%$, respectively. Pollen used in pollinations had germinability and viability over 50\%. Achenes were collected in varying number from each cross (Table 1) except F. chiloensis, though the perennial fruit crop of strawberry (F. $x$ ananassa) is a hybrid of the two species $F$. virginiana and $F$. chiloensis. This was probably due to the low number of pollinated flowers present in F. chiloensis, as reported in Table 1. The results of the GUS histochemical assay performed on the first group of achenes (directly analysed) were showed in Table 2. In all of crosses the achenes collected were GUS positive except for F. vesca cv Zimbaro and F. moscata. In F. moscata, despite having collected 320 achenes, (52 for the first group and 133 which produced seed-derived plants, as reported in Table 3), transgene expression was not observed. This lack of expression could be due to the different ploidy level $(6 n)$ of this species with respect to the donor plant $(8 n)$. Evaluation of transgenic transmission in $F$. vesca showed different results: for the cultivars Ilaria and Snovit we detected GUS activity in achenes but not in seed-derived plants. This evidence was also confirmed by

Table 2

GUS activity performed directly on achenes

\begin{tabular}{lccc}
\hline Cross & \multicolumn{3}{c}{ Achenes } \\
\cline { 2 - 4 } & Analysed & GUS+ & $\%$ \\
\hline cv Teodora clone 10 & 362 & 176 & 48.6 \\
cv Capitola & 21 & 8 & 38.1 \\
F. virginiana & 86 & 51 & 59.3 \\
F. moscata & 52 & 0 & 0 \\
F. vesca cv Snovit & 74 & 6 & 8.1 \\
F. vesca cv Ilaria & 128 & 14 & 10.9 \\
F. Vesca cv Zimbaro & 45 & 0 & 0 \\
\hline
\end{tabular}


Table 3

Evaluation of transgene transmission in plants derived from aseptically germinated achenes (second lot of achenes). For each plant we performed PCR for uidA and nptII genes, selection on kanamycin and GUS histochemical assay

\begin{tabular}{|c|c|c|c|c|c|c|c|}
\hline \multirow[t]{2}{*}{ Cross } & \multirow{2}{*}{$\begin{array}{c}\text { No. of plants } \\
\text { analysed }\end{array}$} & \multicolumn{2}{|c|}{ PCR } & \multicolumn{2}{|c|}{ Selection on kanamycin } & \multicolumn{2}{|c|}{ GUS activity in plants } \\
\hline & & uidA & nptII & Resistant plants & $\%$ & GUS+ & $\%$ \\
\hline cv Teodora clone 10 & 20 & 20 & 20 & 20 & 100 & 20 & 100 \\
\hline cv Capitola & 8 & 2 & 2 & 2 & 25 & 2 & 25 \\
\hline F. virginiana & 16 & 8 & 8 & 8 & 50 & 8 & 50 \\
\hline F. moscata & 133 & 0 & 0 & 0 & 0 & 0 & 0 \\
\hline F. vesca cv Ilaria & 24 & 0 & 0 & 0 & 0 & 0 & 0 \\
\hline F. vesca cv Snovit & 12 & 0 & 0 & 0 & 0 & 0 & 0 \\
\hline F. Vesca cv Zimbaro & 221 & 1 & 1 & 0 & 0 & 1 & 0.5 \\
\hline
\end{tabular}

selection on kanamycin and PCR analysis for $n p t I I$ and uidA genes (Table 3). In F. vesca cv Zimbaro GUS activity was not detected in achenes but, analysing plants obtained from the second group of achenes, we could detect GUS activity in one sample (Table 2). PCR analysis produced expected fragments for uidA and nptII genes also if the same plant, when growth on kanamicyn, showed the typical chlorotic symptoms due to the lack of nptII gene. Some potential causes of the lack of nptII gene expression could include methylation or gene silencing phenomena affecting the nptII gene. Also, even if cross-pollination recipient plants were previously emasculated and the resulting flowers were isolated by using a bag, we can not exclude cross-contamination. To confirm these results further investigation by Southern hybridisation analysis should be done.

The results obtained in Ilaria and Snovit varieties could be due to "false positive" or "background" activities when the GUS assay was performed. Use of the GUS-fusion system in the study of foreign gene expression and in crop plant engineering [28-30] is based on the assumption that there was no detectable intrinsic GUS activity in higher plants [17]. In the last years researchers focused their attention on intrinsic GUS activities in plants. The presence of GUS was evaluated in different species, included pear, corn, pea, tobacco and also in different tissues as fruit walls, seed coats, immature and mature embryos, seedlings and plant at flowering stage [31]. In all of these species intrinsic GUS activity, which was widely distributed in different tissues, was found. The authors also indicated that the germination process could decrease GUS activity. Recently, similar results were obtained in Arasbidopsis taliana, rice, corn, Brassica juncea [32] and tobacco [32, 33]. Also in these species, as wild-type crops, the ubiquitous presence of GUS was detected and it was higher in young tissues than the older or mature tissues. Our results can be explained considering the evidence above reported; achenes are younger tissue than seed-derived plants and also because the germination process decreases GUS activity [31, 32]. To confirm these hypotheses further investigation must be done, including Southern hybridisation and an evaluation of the ubiquitous presence of GUS in wild-type plants of F. vesca.

With regard to self-crossing, GUS expression was detected in $48.6 \%$ of achenes included in the first group (Table 2) compared to achene-derived plants, which showed GUS activity in all plants analysed (Table 3). The reporter genes are thought to be dominant genes [34], consequently all progeny express these traits. In our case, we could detect GUS activity in all of the achene-derived plants, though this expression was found in only 176 achenes (48.6\%). Two hypothesis could explain these results. First, the donor plant could have not been homozygous, but for this to be true in both of the groups of achenes we would have observe the same percentage for GUS expression. Second, the GUS assay could have been inefficient in detecting expression of the reporter genes when achenes were directly analysed [31, 32].

\section{Conclusion}

With regard to the stability and integration of transgenes in plant genomes, our results are in agreement with previous results obtained in strawberry [27] which a more rigorous selection protocol can minimize the risk of chimaerism. 
As expected, genetic exchange occurred at the intra-specific level (Fragaria x ananassa, cv Capitola and $F$. virginiana). Amongst the cultivated strawberry and American wild relatives we confirmed that inter-specific exchange may give rise to a number of viable hybrids. However, in the case of the inter-specific cross using $F$. vesca cv Zimbaro as recipient plant, only one resultant hybrid seedling was observed. This latter observation, which could indicate the possibility of an inter-ploidic cross, may be taken as an index of a possible transmission of transgenes in those environments where $F$. vesca L. is a relative crop of cultivated strawberry, but this needs to be further investigated. Furthermore, the results of this study indicate that the choice of tissue used to evaluate GUS gene expression is important. In fact, as shown by Fragaria vesca and Fragaria $x$ ananassa the results obtained in achenes directly analysed were ambiguous and, consequently, the GUS assay seemed to be less effective in achenes than in leaf tissue. This study also shows the possibility to detect the ubiquitous presence of GUS in wild-type plants of Fragaria spp.

\section{References}

[1] Hancock JF, Scott DH, Lawrence FJ. Strawberries. Fruit breeding, vol. II, Vine and small fruits. In: Janick J, Moore JN, editors. New York USA: Wiley; 1996. p. 419-70.

[2] Miflin B. Crop improvement in the 21st century. J Exp Bot. 2000; 51: 1-8.

[3] Sinclair TR, Purcell LC, Sneller CH. Crop transformation and the challenge to increase yield potential. Trends Plant Sci. 2004; 9: 70-5.

[4] Folta KM, Dhingra A. Transformation of strawberry: The basis for translational genomics in rosaceae. In Vitro Cell Dev Biol Plant. 2006; 42: 482-90.

[5] Qin YH, Teixeira da Silva JAT, Zhang LX, Zhang SL. Transgenic strawberry: State of the art for improved traits. Biotech Adv. 2008; 26: 219-32.

[6] Matzke AJ, Matzke MA. Position effects and epigenetic silencing of plant transgenes. Curr Opin Plant Biol. 1998 ; 1: 142-48.

[7] Bhat SR, Srinivasan S. Molecular and genetic analyses of transgenic plants: Considerations and approaches. Plant Sci. $2002 ; 163: 673-81$.

[8] Nagaya S, Kato K, Ninomiya Y, Horie R, Sekine M, Yoshida K, Shinmyo A. Expression of randomly integrated single complete copy transgenes does not vary in Arabidopsis thaliana. Plant Cell Physiol. 2005; 46: 438-44.

[9] De Block M, Herrera-Estrella L, Van Montagu M, Schell J, Zambryski P. Expression of foreign genes in regenerated plants and in their progeny. EMBO J. 1984; 3: 1681-89.

[10] Ishizaki T, Kumashiro T. Investigations of copy number of transgene, fertility and expression level of an introduced GUS gene in transgenic NERICA produced by Agrobacterium-mediated methods. In vitro Cell Dev Biol Plant. 2011; 47: 339-47.

[11] Haymes KM, Davis TM. Agrobacterium-mediated transformation of 'Alpine' Fragaria vesca, and transmission of transgenes to R1 progeny. Plant Cell Rep. 1998; 17: 279-83.

[12] Westman AL, Levy BM, Miller MB, Gilles GJ, Spira TP, Rajapakse S, Tonkyn DW, Abbott AG. The potential for gene flow from transgenic crops to related wild species: A case study in strawberry. Acta Hort. 2001; 560: 527-30.

[13] Monticelli S, Gentile A, Damiano C. Regeneration and Agrobacterium-mediated transformation in stipules of strawberry. Acta Hort. 2002; 567: 105-7.

[14] Zambryski P, Joos PH, Genetello C, Leemans J, Van Montagu M, Schell J. Ti plasmid vector for the introduction of DNA into plant cells without alteration of their normal regeneration capacity. Embo J. 1983; 2: 2143-50.

[15] Hamill JD, Rounsley S, Spencer A, Gordon T, Rhodes JC. The use of the polymerase chain reaction in plant transformation studies. Plant Cell Rep. 1991; 10: 221-24.

[16] Murashige T, Skoog FA. A revised medium for rapid growth and bioassay with tobacco tissue culture. Physiol Plant. $1962 ; 15: 473-97$.

[17] Jefferson RA. Assaying chimeric genes in plants: The GUS gene fusion system. Plant Mol Biol Rep. 1987 ; 5: $387-405$.

[18] Szankowski I, Briviba K, Fleschut J, Schönherr J, Jacobsen HJ, Kiesecker H. Transformation of apple (Malus domestica Borkh.) with the stilbene synthase gene from grapevine (Vitis vinifera L.) and a PGIP gene from kiwi (Actinidia deliciosa). Plant Cell Rep. 2003; 22: $141-49$.

[19] Richter A, De Kathen A, De Lorenzo G, Briviba K, Hain R, Ramsay G, Jacobsen HJ, Kiesecker H. Transgenic peas (Pisum sativum) expressing polygalacturonase inhibiting protein from raspberry (Rubus idaeus) and stilbene synthase from grape (Vitis vinifera) Plant Cell Rep. 2006; 25: 1166-73.

[20] Cervera M, Pina JA, Juarez J, Navarro L, Pena L. A broad exploration of a transgenicpopulation of citrus: Stability of gene expression and phenotype. Theor Appl Genet. 2000; 100: 670-77.

[21] Dominguez A, Fagoaga C, Navarro L, Moreno P, Pena L. Regeneration oftransgenic citrus plants under non selective conditions results in high-frequency recovery of plants with silenced transgenes. Mol Genet Genom. 2002; 267: 544-56.

[22] Gao C, Jinxing L, Nielsen KK. Agrobacterium-mediated transformation of meadow fescue (Festuca pratensis Huds.). Plant Cell Rep. 2009; 28: 708-14. 
[23] Husaini AM, Abdin MZ. Development of transgenic strawberry (Fragaria $\times$ ananassa Duch.) plants tolerant to salt stress. Plant Sci. 2008; 174: 446-55.

[24] Husaini AM. Pre and post-agroinfection strategies for efficient leaf disk transformation and regeneration of transgenic strawberry plants. Plant Cell Rep. 2010; 29: 97-110.

[25] Akiyoshi DE, Klee H, Amasino RM, Nester EW, Gordon MP. T-DNA of Agrobacterium tumefaciens encodes an enzyme of cytokinin biosynthesis. Proc Natl Acad Sci USA. 1984; 80: 5994-98.

[26] Buchmann I, Marner FJ, Schroder G, Waffenschmidt W, Schroder J. Tumor genes in plants: T-DNA encoded cytokinin biosynthesis. Embo J. 1985; 4: 853-59.

[27] Mathews H, Dewey V, Wagoner W, Bestwick RK. Molecular and cellular evidence of chimeric tissue in primary transgenics and elimination of chimaerism through improved selection protocols. Trans Res. 1998; 7: 123-9.

[28] Gisbert C, Arrillaga I, Roig LA, Moreno V. Acquisition of a collection of Lycopersicon pennelli (Corr. D'Arcy) transgenic plants with uidA and nptII marker genes. J Hort Sci Bio. 1999; 74: 105-9.

[29] Padilla IMG, Golis A, Gentile A, Damiano C, Scorza R. Evaluation of transformation in peach Prunus persica explants using green fluorescent protein (GFP) and beta-glucuronidase (GUS) reporter genes. Plant Cell TissOrg Cult. 2006; 84: (3) 309-14.

[30] Hamama L, Voisine L, Peltier D, Boccon-Gibod J. Shoot regeneration and genetic transformation by Agrobacterium tumefaciens of Hydrangea macrophylla Ser. leaf disc. Sci Hort. 2011; 127: 378-87.

[31] Hu C, Chee PP, Chesney RH, Zhou JH, Miller PD, O’Brien WT. Intrinsic GUS-like activities in seed plants. Plant Cell Rep. 1990; 9: 1-5.

[32] Sudan C, Prakash S, Bhomkar P, Jain S, Bhalla-Sarin N. Ubiquitous presence of beta-glucuronidase (GUS) in plants and its regulation in some model plants. Plant Cell Rep. 2006; 224: 853-64.

[33] Pret'ovà A, Obert B, Wetzstein HY. Leaf development stage and tissue location affect the detection of $\beta$-glucuronidase in transgenic tobacco plants. Biotechnol Lett. 2001; 23: 555-58.

[34] Puchta H. Marker-free transgenic plants. Plant Cell Tiss and Org Cult. 2003; 74: 123-34. 